\title{
Pemanfaatan Remitan Ekonomi dan Ketergantungan Migran Kembali Bekerja di Luar Negeri ${ }^{1}$
}

\author{
Suyanto \\ Departemen Budaya, Fakultas Ilmu Budaya Universitas Diponegoro Semarang \\ Email: suyanto@undip.ac.id
}

\begin{abstract}
The general objective of this study is to examine the use of economic remittances and constraints in economically productive use and their dependence as workers abroad. This study selected a sample of the Kendal Regency region. Determination of the sample using random sampling techniques and the selection of informants using purposive sampling technique. Data collection uses non-participatory observation, structured interviews, and indepth interviews. The use of economic remittances to meet daily needs, the cost of education, buy land and build houses, buy secondary goods, and buy productive goods. Their dependence continues to work abroad due to the low access to land and the shifting of the cultivation of agricultural commodities from food (rice) to industrial raw materials (tobacco), the narrow employment opportunities in the area, job opportunities in destination countries, wage rates much higher than in Indonesia, and the use of remittances which tend to be nonproductive.
\end{abstract}

Keywords: returning migrants, economic remittances, dependency, working abroad

\section{Pendahuluan}

Indonesia merupakan sumber terbesar kedua bagi migrasi tenaga kerja ke luar negeri setelah Filipina. Pada kuartal pertama tahun 2012, lebih dari 4 juta tenaga kerja Indonesia (TKI) bekerja di luar negeri terutama di Asia Tenggara dan Timur Tengah (Doi, 2012:36). Bahkan, pada tahun 2013 Filipina telah tergeser oleh Indonesia dalam pengiriman tenaga kerja ke luar negeri dengan jumlah 6,5 juta orang yang tersebar di 142 negara dan berasal dari 392 daerah kabupaten / kota di Indonesia (Nurhayat, 2013; Suara Pembaruan, 27-12-2013). Angka ini hanya mendasarkan pada data tenaga kerja yang bekerja di luar negeri secara legal. Dalam kenyataan, TKI yang bekerja secara illegal di luar negeri justru lebih banyak, terutama di kawasan Asia Tenggara, khususnya Malaysia, walaupun gejala itu sekarang sudah berbalik, TKI illegal sekitar sepertiga daripada TKI yang legal (Kompas, 19 Juli 2013).

Dari studi terdahulu menunjukkan bahwa para migran kembali (mantan TKI) semacam "ketagihan" untuk selalu bekerja di luar negeri. Hal ini lebih disebabkan oleh

\footnotetext{
${ }^{1}$ Tulisan ini merupakan bagian dari Penelitian Program Penelitian Terapan Unggulan Perguruan Tinggi (PTUPT) yang dibiayai oleh Direktorat Riset dan Pengabdian Masyarakat, DirjenPenguatan Riset dan Pengembangan Kemenristek Dikti, No Kontrak: 101-86/UN7.P4.3/PP/2018.
} 
pemanfaatan remitan yang cenderung untuk kebutuhn konsumtif dan investasi. Pemanfaatan remitan untuk usaha produktif hanya dilakukan oleh sebagian kecil mantan TKI. Karena hal itu, maka para mantan TKI ketika pulang ke Indonesia sebagai sosok yang royal berbelanja dan gaya hidup yang berubah daripada sebelum bekerja di luar negeri dan dalam waktu beberapa bulan di Indonesi, sudah kehabisan uang. Dalam kondisi semacam ini, tidak ada pilihan lain bagi mereka kecuali berangkat lagi sebagai TKI. Kondisi semacam ini terjadi hampir berulang-ulang bagi sebagian terbesar mantan TKI (Suyanto 2003). Hal semacam ini sangat fenomenal terjadi di daerah asal kantong migran di Indonesai, seperti NTT, NTB dan Baweyan (Jawa Timur) (Mantra,1999). Kabupaten Kendal sebagai daerah asal migran internasional terbesar di Jawa Tengah yang berada di pantai utara Jawa Tengah menjadi fokus rencana penelitian ini.

Penduduk melakukan migrasi, dalam hal ini migrasi internasional seperti yang dilakukan oleh TKI ditentukan oleh berbagai faktor pendorong di daerah asal ( $p u s h$ factors) dan faktor penarik di daerah tujuan (pull factors) (Lee dalam Mantra, 1995). Faktor pendorong utama adalah masalah ekonomi, yakni kesempatan kerja yang sangat terbatas dan pendapatan yang rendah di Negara asal (Indonesia) dan peluang kerja yang luas dan tingkat pendapatan yang lebih tinggi di Negara tujuan. Lebih memprihatinkan lagi temuan Haris (2002: 24) bahwa bermigrasi menjadi TKI sebagai suatu strategi untuk bertahan hidup (survival strategy) migran dan keluarganya.

Akan tetapi, beberapa penelitian menunjukkan bahwa kemampuan mantan TKI tidak seluruhnya dapat dimanfaatkan dalam perilaku produktif ekonomi di daerah asal. Hal ini disebabkan oleh kesempatan kerja di daerah asal sangat terbatas dan pola pikir mantan TKI yang belum mempunyai perencanaan apa yang akan dilakukan setelah mereka tidak menjadi TKI lagi (Pitoyo, 2010). Selain itu, pada umumnya mereka berasal dari keluarga kurang mampu dan berpendidikan rendah, masih berusia muda, rata-rata 35 tahun, dan mempuyai pengalaman kerja yang cukup baik sehingga peran mereka dalam menopang kehidupan perekonomian rumah tangga masih sangat diharapkan (Trisnaningsih, 2013). Hal ini semestinya perlu mendapatkan perhatian dan penanganan yang serius dari berbagai pihak terkait agar tidak menambah jumlah pengangguran ketika sudah kembali lagi di daerah asal (Indonesia).

Migrasi kembali adalah situasi migran kembali ke negara asal atas pilihan sendiri, sering setelah bertempat tinggal di luar negeri dalam periode waktu yang cukup signifikan (Dustmann dan Weiss, 2007: 3). Indonesia membatasi TKI yang bekerja di luar negeri dalam kurun waktu dua tahun dan setelah itu dapat diperpanjang lagi. Kontrak kerja itu berdasarkan UndangUndang Nomor 39 Tahun 2004 tentang Penempatan dan Perlindungan Tenaga Kerja Indonesia di Luar Negeri, pasal 56 ayat (1) yang menyatakan bahwa "Perjanjian kerja dibuat untuk waktu paling lama dua tahun dan dapat diperpanjang untuk jangka waktu paling lama dua tahun". Akan tetapi, masa kontrak kerja TKI sering berdasarkan regulasi Negara tujuan. Artinya, kontrak kerja TKI tidak selamanya dua tahun, bergantung regulasi yang diberlakukan di Negara tempat TKI bekerja, di Jepang misalnya empat tahun, Korea tiga tahun dan sebagainya (Suyanto, 2003). Mereka yang telah berakhir kontrak kerja bisa kembali terlebih dahulu ke Indonesia dan kembali lagi ke Negara tujuan atau kontrak langsung diperpanjang tanpa harus kembali dahulu ke Indonesia. Mereka yang kembali ke Indonesia dalam kurun waktu tertentu maupun secara permanen ini dikenal sebagai migran kembali atau mantan TKI. Mantan TKI didefinisikan sebagai migran kembali ke negara asal atas pilihan sendiri dan/atau telah berakhirnya izin tinggal atau kontrak kerja di negara tujuan (Trisnaningsih, 2013).

Dalam tataran makro, migran kembali berpengalaman meningkatkan rata-rata modal manusia (human capital) bagi negara pengirim (Mayr and Peri, 2008) dan 
meningkatkan penghasilan dan menjadi lebih modern, terutama bagi individu yang bekerja di pabrik atau lembaga modern (Inkelas dan Smith dalam Budiman, 2000). Migran kembali dengan kualitas modal manusianya membawa sejumlah modal yaitu modal finansial, modal sosial, modal manusia, kepemimpinan, dan pelatihan.

Modal manusia mencakup lima komponen yaitu aspek kognitif, konatif, psikomotorik, afektif, dan sumber daya material-fisik (Sulistiyani, 2004:80; Mayr and Peri, 2008). Kondisi kognitif merupakan kemampuan berpikir yang berlandaskan pengetahuan dan wawasan dalam mencari solusi atas permasalahan yang dihadapi. Kondisi konatif adalah suatu sikap perilaku yang mengarah pada sensitivitas pembangunan dan pemberdayaan. Kondisi psikomotorik sebagai kecakapan ketrampilan yang dimiliki individu dalam mendukung pemabangunan masyarakat. Dan kondisi afektif adalah sense yang dimiliki oleh individu yang diharapkan dapat diintervensi untuk mencapai keberdayaan sikap dan perilaku. Dalam meningkatkan kesejahteraan individu, khususnya mantan TKI, pengembangan modal manusia didukung oleh modal sosial.

\section{Metode}

Secara spasial, Kabupaten Kendal dipilih sebagai sampel wilayah (lokasi) penelitian ini berdasarkan beberapa pertimbangan. Pertama, Kabupaten Kendal merupakan kantong daerah asal migran internasional di Jawa Tengah. Hal ini ditunjukkan oleh jumlah TKI yang dikirim ke luar negeri dari Jawa Tengah dalam beberapa tahun terakhir (2009-2013) menempatkan Kabupaten Kendal sebagai pengirim TKI terbanyak (BPS Provinsi Jawa Tengah, 2013). Kedua, para mantan TKI di Kabupaten Kendal memiliki ketergantungan yang tinggi dengan bekerja di luar negeri. Hal ini disebabkan oleh pola pemanfaatan remitan (materi) yang bersifat konsumtif sehingga ketika penghasilan telah habis, mereka pada umumnya akan kembali bekerja di luar negeri (Suyanto, 2003). Ketiga, karena besarnya jumlah penduduk usia produktif yang bekerja di luar negeri di Kabupaten Kendal, maka jumlah remitan (materi) juga besar.

Data yang dibutuhan dalam penelitian ini adalah data skunder dan primer.Data primer meliputi data kuantitatif dan kualitatif. Data primer kuantitatif dijaring mengguankan wawancara terstruktur. Adapun pengumpulan data primer kualitatif dilakukan dengan observasi nonpartisipatoris dan wawancara mendalam. Analisis data menggunakan analisis kuantitatif dan kualitatif. Analisis kuantitatif menggunakan analisis statistik deskriptif menggunakan tabel distribusi frekuensi tunggal dan silang. Analisis statistik deskriptif (distribusi tunggal maupun silang) dipergunakan untuk analisis karakteristik sosial demografi, modal manusia, dan modal sosial, serta kesejahteraan mantan TKI. Sedangkan analisis kualitatif dengan menggunakan analisis deskriptif, interpretasi, dan kategoris (Ricoeur,2014).

\section{Hasil \& Pembahasan}

\subsection{Remitan \& Pemanfaatannya}

Remitan merupakan sarana hubungan para migran di daerah tujuan dengan daerah asal. Hal ini dapat dipahami karena migran mempunyai istri atau suami, anak, saudara, teman, kenangan masa kecil dan sebagainya di daerah asal, sehingga sulit untuk meninggalkan daerah asal. Keterikatan migran dengan daerah asal sangat kuat biasanya terjadi di negara sedang berkembang termasuk di dalamnya Indonesia (Norris, 1972). Adapun yang dimaksud remitan adalah penghasilan yang diperoleh di daerah tujuan yang dibawa pulang dikirim dikirimkan ke daerah asal (Mantra 1999). Remitan dapat berwujud berbagai bentuk seperti uang, barang dan ide. Namun remitan yang paling besar perannya terhadap keluarga dan daerah asal migran adalah yang berupa uang. 
Sedangkan ide juga cukup mewarnai para migran kembali, khususnya dalam hal sikap seperti dalam mendidik anak, pandangannya tentang suatu nilai dan kadang perilaku serta ide pembangunan.

Para mantan TKI di Kendal mengirimkan hasil kerjanya berkisar dua hingga 10 bulan, namun ada yang hanya kirim satu hingga tiga bulan pertama, sisanya dibawa ketika pulang. Para pekerja yang bekerja di Timur Tengah, penghasilannya tiap bulan 600 real. Apabila kurs satu real Rp 2.500 misalnya, para migran setiap bulan mempunyai 1,5 juta. Apabila masa kontrak dua tahun ( 24 bulan), maka penghasilan mereka dalam satu kali masa kontrak 30 juta rupiah. Oleh karena itu wajar jika koiribusi mereka membeli tanah dan membangun rumah. Adapun pengaruh remitan di daerah para mantan TKI adalah untuk mencukupi kebutuhan sehari-hari, beaya pendidikan anak-anak, membeli tanah dan membangun rumah, usaha produktif dan membeli barang-barang sekunder. Lima hal tersebut diuraikan satu persatu di bawah ini.

\section{Memenuhi Kebutuhan Sehari-hari}

Walaupun latar belakang utama mereka bekerja di luar negeri karena ingin memiliki rumah sendiri, namun dalam kenyataannya pemanfaatan remitan juga untuk menopang kebutuhan sehari-hari. Namun hal ini hanya bersifat membantu kekurangan apabila penghasilan suami di rumah tidak dapat untuk mencukupi kebutuhan sehari-hari, seperti makan,biaya sosial dan yang sejenisnya. Hal ini disebabkan orientasi penghasilan kerja di luar negeri untuk kebutuhan yang fundamental dan cukup besar seperti membeli tanah dan membuat rumah.

Sebelum marak migrasi internasional, dalam masyarakat Jawa, khususnya pedesaan, hidup suatu pandangan adanya \&twit lanang dan \&twit wedok. Duwit lanang (lelaki) artinya adalah penghasilan yang diperoleh oleh seorang laki-laki (suami), biasanya berjumlah besar yang pemanfaatannya untuk keperluan rumah tangga yang bersifat besar seperti membeli tanah, supitan, biaya pendidikan, membangun rumah, dan sebagainya. Duwitlanang ini diperoleh dari hasil penjualan teranak, perkebunan (tanaman keras), hasil buruh, dan sebagainya. Sedangkan duwit wedok (uang perempuan) merupakan penghasilan istri atau perempuan ketika mereka bekerja di luar rumah (ruang publik) seperti hasil dari tanam sayur-sayuran, hasil sampingan seperti membuat keset dan kerajinan yang lain yang bersifat kerja sambilan. Duwit wedok dipandang sebagai hasil harian yang dimanfaatkan untuk mencukupi kebutuhan sehari-hari seperti makan, nyumbang, arisan, uang saku anak-anak dan sejenisnya (Kutanegara dalam Irwan Abdullah, 1997: 208 - 209).

Namun bagi kaum migran, khususnya TKI, pandangan di atas tidak berlaku lagi, justru pemanfaatannya berlaku sebaliknya bahwa duwit wedok untuk memenuhi kebutuhan rumah tangga yang bersifat besar seperti membeli tanah, membangun rumah, biaya pendidikan anak, membeli toko, motor, mobil dan sebagainya, sementara duwit lanang justru untuk mencukupi kebutuhan sehari-hari seperti makan, kondangan, sangu anak dan sebagainya.

\subsection{Biaya Pendidikan Anak}

Salah satu alasan utama responden melakukan mobilitas tenaga kerja ke luar negeri atau menjadi TKI adalah untuk membeayai pendidikan anak-anak. Responden yang ke luar negeri dengan alasan ini mencapai 29,41 persen atau lima orang. Mereka umumnya menyadari bahwa dirinya tidak dapat sekolah karena alasan ekonomi orang tua sehingga mereka harus berhenti sekolah karena orang tua tidak dapat membiayai dan harus membantu orang tua mencukupi kebutuhan rumah tangga. Merekapun menyadari karena pendidikan yang terlalu rendah sehingga lapangan kerja yang dimasuki adalah 
pekerjaan kasar, seperti pembantu rumah tangga atau buruh tani. Hal tersebut diungkapkan oleh Sodiyah (35 tahun) TKI yang bekerja di Malaysia selama 4 tahun menuturkan sebagai berikut:

"Saya dan bapak bingung menghadapi masa depan anakanak. Saya saja sekolahnya hanya kelas 3 SD, maka anakanak saya untuk sekolah yang tinggi, paling tidak SMP lah. Anak saya tiga, yang paling besar sekarang di Malaysia sudah 2 tahun, nomor duanya baru tamat SMP dan yang paling kecil baru SMP kelas I. Saya tidak mungkin dapat menyekolahkan anak-anak kalau tidak ke Malaysia karena saya tidak mempunyai pekerjaan apa-apa kecuali tandur (menanam padi - pen) dan kalau musim panen derep (memetik padi orang lain dengan mendapatkan ongkos berupa padi; biasanya mendapat 12 persen dari padi yang dipetik) dan petik daun tembakau."

Kondisi SDM yang rendah, tidak hanya dialami oleh Kabupaten Kendal, tetapi ini merupakan kondisi umum yang dialami Indonesia. Padahal seperti yang diungkapkan Gardiner (dalam Sukamdi, 1997) SDM yang rendah berkaitan dengan upah rendah dan tingkat kompetisinya pun rendah. Hal ini berkaitan dengan ciri-ciri yang tidak menguntungkan seperti: tingkat ketergantungan tinggi, inisiatif kurang, produktivitas rendah, cenderung dipekerjakan pada pekerjaan yang sederhana karena modalnya Iebih pada kondisi fisik semata (Simanjuntak dalam Sukamdi 1999).

\subsection{Membeli Tanah dan Membangun Rumah}

Sebagian besar TKI menyatakan bahwa dirinya bekerja di luar negeri sebagai TKI dengan tujuan agar dapat mempunyai rumah sendiri. Responden yang menyatakan hal ini mencapai 70,59 persen. Jadi, alasan utama mereka ingin bekerja di luar negeri hanya dua, di samping alasan ingin mempunyai rumah sendiri, alasan yang lain adalah untuk membeayai pendidikan anak-anak. Sebelum berangkat 'ke luar negeri, hanya satu orang responden $(5,88$ persen) yang mempunyai rumah sendiri, itupun pemberian orang tuanya. Sedangkan 94,12 persen responden belum mempunyai rumah sendiri. Mereka hampir semuanya bergabung dengan orang tua, hanya satu responden yang sudah berpisah dengan orang tua dengan mengontrak rumah.

Bagi mereka mempunyai rumah merupakan hal yang sangat mewah, merupakan suatu utopia karena penghasilan yang diperoleh untuk memenuhi kebutuhan sehari-hari saja sering kekurangan. Oleh karena itu, hal ini merupakan suatu tekanan (stress) yang sangat kuat bagi mereka untuk pergi ke luar negeri, apapun risiko yang dihadapi. Kenyataan ini membenarkan pendapat Mantra (1999), makin besar kebutuhan yang tidak dapat dipenuhi, semakin besar stress yang dialami seseorang. Apabila stress sudah di luar batas toleransi, maka orang tersebut akan pindah ke daerah lain tempat kebutuhannya dapat terpenuhi. Seseorang yang mengalami hal tersebut akan pindah dari daerah yang mempunyai nilai manfaat (place utility) yang rendah menuju tempat yang mempunyai nilai manfaat yang lebih tinggi. Rumah atau tempat berteduh menurut Abraham Maslow merupakan kebutuha dasar atau fisiologis manusia yang mempunyai posisi sederajat dengan kebutuhan yang lain, seperti udara, air, makanan, tidur dan seks (Goble, 1987:92). Oleh karena itu wajar jika mereka dalam memenuhi kebutuhan tersebut dengan cara apapun dan apapun risikonya.

\subsection{Kebutuhan Barang Sekunder}

Pola pemanfaatan remitan kaum buruh migran, khususnya TKI di kabupaten Kendal, orientasi pertama adalah pemenuhan kebutuhan pokok berupa rumah. Setelah hal tersebut terpenuhi, maka kebutuhan selanjutnya yang dipenuhi ada/ah kebutuhan sekunder seperti 
kendaraan bermotor, TV, dan perabotan rumah tangga yang lain. Hal ini nampaknya berlaku untuk buruh migran yang sudah berumah tangga, khususnya TKI yang ketika berangkat belum memiliki rumah. Jika buruh migran berstatus anak, (ikut orang tua) justru polanya terbalik, yaitu pemanfaatan remitan pertama kali untuk hal-hal sekunder, seperti membeli kendaraan bermotor, membangun rumah orang tua, membeli TV, clan perabotan rumah tangga yang lain.

Menurut Maslow, manusia merupakan binatang yang berhasrat dan jarang mencapai taraf kepuasan yang sempurna kecuali untuk suatu saat yang terbatas. Dengan demikian, begitu hasrat berhasil dipuaskan, maka segera muncul hasrat yang lain atau berikutnya. Ini artinya bahwa kebutuhan manusia tidak hanya bersifat fisiologis, namun juga bersifat psikologis. Oleh karena itu, merupakan hal yang wajar jika para mantan TKI setelah kebutuhan fisiologis terpenuhi, berusaha untuk memenuhi kebutuhan yang bersifat psikologis.

\subsection{Kepemilikan Parang Produktif}

Para migran kembali, setelah kebutuhan primernya terpenuhi, seperti kepemilikan rumah, sebagian langsung merambah kepemilikan barang sekunder seperti disebutkan di atas. Namun, sebagian yang lain memanfaatkan remitan langsung untuk usaha produktif dengan jalan dibelikan barang-barang yang bersifat menghasilkan. Adapun halhal yang bersifat produktif yang dimiliki oleh mantan TKI adalah berupa sarana usaha seperti mobil (dua orang), mesin jahit (satu orang), menambah modal dagang dan membeli toko (satu orang).

Mantan TKI yang memanfaatkan remitarmya untuk usaha produksi adalah mereka atau suaminya ketika sebelum ke luar negeri telah menekuni bidang usaha tersebut. Inayah (30 tahun) misalnya, karena suaminya seorang sopir truk, maka setelah dapat membeli tanah dan membangun rumah, ketika pulang hasilnya dipergunakan untuk membeli mobil L 300 seharga 17 juta. Hasil dari mobil yang dimilikinya jika sedang musim panen tembakau, setiap hari dapat menghasilkan Rp 100.000,-.

Sedangkan seorang mantan TKI yang lain, karena suaminya berdagang di pasar, sisa hasil yang dipergunakan untuk membangun rumah dipergunakan untuk membeli toko seharga 22,5 juta rupiah. Toko tersebut saat ini sudah merupakan sumber pendapatan ekonomi rumah tangga. Bahkan dia sudah tergolong mampu dalam bidang ekonomi.

Namun, bagi mantan TKI atau suaminya sebelum bekerja di luar negeri tidak bergerak di bidang bisnis atau hal-hal yang bersifat produktif, seperti buruh, petani dan tukang becak dalam memanfaatkan remitan hanya untuk hal-hal yang bersifat non produktif atau lebih ekstrim lagi hal-hal yang bersifat konsumtif. Dengan demikian, kontribusi remitan di dalam ekonomi rumah tangga, selain untuk pemenuhan kebutuhan primer seperti rumah, kurang signifikan. Kecenderungan pemanfaatan remitan mereka, setelah terpenuhi kebutuhan primer, langsung ke kebutuhan sekunder, seperti membeli motor roda dua, televisi, dan perlengkapan rumah tangga.

\section{Simpulan}

Pengiriman TKI dari Kabupaten Kendal ke luar negeri, khususnya ke Timur Tengah merupakan perintis pelaksanaan ekspor jasa tenaga kerja ke luar negeri karena hal ini berjalan sejak Pelita II (periode 1979-1984). Hal ini berkaitan dengan latar belakang daerah tersebut yang merupakan daerah religius (Islam) disampinga tingkat pendapatan yang sangat rendah akibat rendahnya akses terhadap tanah dan beralihnya penanaman komoditi pertanian dari bahan pangan (padi) ke komoditi bahan baku industri (tembakau) 
serta sempitnya lapangan pekerjaan yang tersedia di daerah tersebut. Tiga hal tersebut merupakan faktor pendorong yang kuat bagi mereka untuk melakukan mobilitas tenaga kerja internasional, khususnya ke Timur Tengah yang kesemuanya ke Arab Saudi. Sedangkan faktor penarik mereka rnelakukan mobilitas internasional adalah kesempatan kerja di sana terbuka lebar, tingkat upah jauh lebih tinggi daripada di Indonesia, dan keinginan untuk menjalankan ibadah haji atau umroh.

Migran kembali di Kendal didominasi oleh perempuan karena ekonomi rumah tangga jika dalam kondisi kritis, ada kecenderungan perempuan tampil ke depan mengatasi masalah tersebut, namun apabila kondisi sudah mulai membaik, lakilaki kembali memegang kendali keadaan.

Remitan yang mereka bawa ke daerah asal lebih didominasi berwujud uang daripada barang atau ide. Remitan yang mereka bawa ke daerah asal, tidak hanya merupakan sumbangan terdap devisa negara, tetapi lebih dari itu dapat mengangkat koindisi ekonomi rumah tangga sangat sinifikan. Tenaga kerja wanita hampir seluruhnya ketika belum bekerja di luar negeri tidak memiliki rumah, hanya 5,88 persen TKI yang sudah mempunyai rumah sendiri yang merupakan pemberian orang tua, namun sekembali mereka dari luar negeri sebagai TKI sebanyak 82,36 persen dapat memiliki rumah dari hasil bekerja di luar negeri, bahkan 57,14 persen diantara mereka memiliki rumah beserta tanahnya dari hasil tersebut. Sebagian dari mereka, selain sudah dapat memiliki rumah sendiri, masih dapat membeli barang produktif, seperti mobil niaga, toko, dan saran usaha yang lain yang merupakan sumber pendapatan seharihari.

Setelah menjadi migran kembali, para perempuan pada umumnya mempunyai posisi tawar yang relatif kuat terhadap suami (laki-laki). Para mantan TKI mempunyai posisi dominan dalam mengalokasikan remitan dan kontrol atas pemanfaatan remitan yang bersifat produktif.

\section{Daftar Pustaka}

Abdullah, Irwan. 1997. Sangkan Paran Gender. Yogyakarta: Pustaka Pelajar.

BPS. 2016. Kendal dalam Angka 2015. Kendal: BPS Kabupaten Kendal.

BPS. 2016. Cilacap dalam Angka 2015. Kendal: BPS Kabupaten Kendal.

BPS. 2016. Jawa Tengah dalam Angka 2015. Semarang: BPS Provinsi Jawa Tengah.

Budiman, Arief. 2000. Teori Pembangunan Dunia Ketiga. Jakarta: Gramedia Pustaka Utama.

Doi, Yoko. 2012. Bagaimana Membantu TKI Menciptakan Kesejahteraan. LIONMAG. The Inflight Magazine of Lion Air. Edisi November. Hal. 36-38.

Dustmann, Christian, and Yoram Weiss.2007. Return Migration: Theory and Empirical Evidence. CreAM Discussion Paper Series CPD No. 02/07. Departement of Economics and CreAM (Center for Research and Analisys of Migration), University College London.

Haris, Abdul dan Nyoman Adika. 2002. Dinamika Kependudukan dan Pembangunan di Indonesia: Dari Perspektif Makro ke Realitas Mikro. Yogyakarta: LESF I.

Kompas. 2013. "KEMBALI terancam Diusir".19 Juli, hlm.1.

Mantra, Ida Bagus, dkk. 1999. Mobilitas Tenaga Kerja Indonesia ke Malaysia: Studi Kasus Flores Timur, Lombok Tengah, Pulau Bawean. Yogyakarta: Pusat Penelitian Kependudukan UGM.

Goble, Frank G. 1987. Mazhab ketiga: Psikologi Humanistik Abraham Maslow. Yogyakarta: Kanisius.

Mayr, Karin and Giovani Peri. "Return Migration as A Chanel of Brain Gain". Working Paper 14039. National Bureau of Economic Research. Massachusetts Avenue. Cambridge,M.A. 
Norris. Robert E. 1972. "Migration as Spatial Interaction". Journal of Geography Volume 71, hlm $294-301$.

Suyanto et al. 2003. "Mobilitas Internasional Tenaga Kerja Wanita: Studi Perubahan Sosial Ekonomi Rumah Tangga Tani Desa Banjarsari Kecamatan Nusawungu, Cilacap". Laporan Penelitian Kajian Wanita, Lembaga Peneltian Universitas Diponegoro.

Pitoyo, Joko Agus. 2010. "Bina Keluarga Migran Menuju Sejahtera: Pemanfaatan Remitan Produktif". Dalam Tukiran, AJ Pitoyo, dan PM Kutannegara (Eds), Akses Penduduk Miskin terhadap Kebutuhan Dasar. Yogyakarta:PPSK UGM.

Singarimbun, Masri dan Sofian Effendi.1995. Metode Penelitian Survai. Jakarta: LP3ES.

Sulitiyani, Ambar Teguh. 2004. Kemitraan dan Model-model Pemberdayaan. Jogjakarta: Gava Media.

Tjiptono, Fandy. 2012. Human Capital Theory dan Kelangsungan Perusahaan. Dalam Pengembangan Human Capital Perspektif National, Regional, dan Global. Sanerya Hendrawan, Indraswari, dan Silvia Yasid (eds). Yogyakarta: Graha Ilmu.

UU No. 39/2004. Penempatan dan Perlindungan Tenaga Kerja Indonesia di Luar Negeri.

Nurhayat, Wiji. 2013. "Jumlah TKI Capai 6,5 Juta, Tersebar di 142 Negara" dalam detikfinance.com, diunduh 14 Maret 2013,17:40. 